\title{
Terrestrial Water Storage Changes of Permafrost in the Three-River Source Region of the Tibetan Plateau, China
}

\author{
Min Xu, ${ }^{1}$ Shichang Kang, ${ }^{1,2}$ Qiudong Zhao, ${ }^{1}$ and Jiazhen $\mathrm{Li}^{1}$ \\ ${ }^{1}$ State Key Laboratory of Cryospheric Science, Cold and Arid Regions Environmental and Engineering Research Institute, \\ Chinese Academy of Sciences, Lanzhou 730000, China \\ ${ }^{2}$ CAS Center for Excellence in Tibetan Plateau Earth Sciences, Chinese Academy of Sciences, Beijing 100101, China
}

Correspondence should be addressed to Shichang Kang; shichang.kang@lzb.ac.cn

Received 11 October 2015; Revised 16 December 2015; Accepted 19 January 2016

Academic Editor: Rogier Van Der Velde

Copyright (C) 2016 Min Xu et al. This is an open access article distributed under the Creative Commons Attribution License, which permits unrestricted use, distribution, and reproduction in any medium, provided the original work is properly cited.

\begin{abstract}
Changes in permafrost influence water balance exchanges in watersheds of cryosphere. Water storage change (WSC) is an important factor in water cycle. We used Gravity Recovery and Climate Experiment (GRACE) satellite data to retrieve WSC in the Three-River Source Region and subregions. WSC in four types of permafrost (continuous, seasonal, island, and patchy permafrost) was analyzed during 2003-2010. The result showed that WSC had significant change; it increased by $9.06 \pm 0.01 \mathrm{~mm} / \mathrm{a}\left(21.89 \pm 0.02 \times 10^{9} \mathrm{~m}^{3}\right)$ over the Three-River Source Region during the study period. The most significant changes of WSC were in continuous permafrost zone, with a total amount of about $13.94 \pm 0.48 \times 10^{9} \mathrm{~m}^{3}$. The spatial distribution of WSC was in state of gain in the continuous permafrost zone, whereas it was in a state of loss in the other permafrost zones. Little changes of precipitation and runoff occurred in study area, but the WSC increased significantly, according to water balance equation, the changes of runoff and water storage were subtracted from changes of precipitation, and the result showed that changes of evaporation is minus which means the evaporation decreased in the Three-River Source Region during 2003-2010.
\end{abstract}

\section{Introduction}

Permafrost is one of the largest components of the cryosphere by areal extent [1]. The permafrost in Tibetan Plateau (TP) is present in the midlatitudes, and thus it is considered more sensitive to climatic warming than the higher latitudinal arctic region $[2,3]$. The ecosystems and surface and groundwater processes of TP are experiencing modification due to the thawing of permafrost in response to climate change in China [4]. As a specific regional aquitard, permafrost obstructs or significantly weakens the spatiotemporal hydraulic connection between groundwater and surface water, and it plays a decisive role in the formation of cold groundwater, transport processes, and the pattern of distribution of groundwater and its pathways [5].

Terrestrial hydrological processes in midlatitude regions are controlled by the presence or absence of permafrost and the thickness of the active layer; the top layer of soil that thaws and freezes as part of the seasonal cycle $[6,7]$. The permafrost region of the TP receives little precipitation in winter and spring; there has been little variation in this pattern of precipitation over the past 50 years [8]. In contrast with the Eurasian Arctic rivers, the discharge of rivers in the TP permafrost zone, including the Yangtze River and the Yellow River, has decreased significantly by $12.4-21.7 \%$ in recent decades $[9$, 10]. The distribution of runoff has flattened because of degradation of the permafrost [11]. This has had significant effect on groundwater, water recycling, and water resources, which has led to the deterioration of the ecological environment [12].

The Three-River Source Region constitutes an important part of the TP; it is known as "Asia's Water Tower." Approximately $49 \%$ of the total water volume of the Yellow River, $15 \%$ of the Lancang River, and a considerable amount of the Yangtze River volume come from the Three-River Source Region. The area also has important influence on ecological security and economic development in China [13], and its unique geographic environments and climatic conditions play significant roles in the climate change of China, East 
Asia, and the world $[14,15]$. Initially, the research region has focused on the source of the Yellow River. The relationship between runoff and precipitation and the response of runoff to both land cover change and climate change have been the main topics in earlier studies [16-18]. Subsequently, the research region has been expanded into the source of the Yangtze River and the entire Three-River Source Region. Furthermore, the research topics have also widened to include additional hydrological and climatological elements such as the relationships between runoff and precipitation, temperature, and evaporation $[13,15,19,20]$. However, previous research has neglected the water storage change (WSC) of the permafrost in the Three-River Source Region. Consideration of WSC, including surface water, snow and ice, soil moisture, and groundwater, is essential for understanding a wide range of hydrological, climatological, and ecological processes and is important for water resource management [21, 22].

In situ monitoring of regional-scale WSC is extremely limited, especially in remote areas of the TP. Traditional remote sensing satellites can be used to detect the soil moisture of the land surface to depths of only tens of centimeters, and the spatial distribution of field stations for verification purposes is poor. However, to a certain extent, the Gravity Recovery and Climate Experiment (GRACE) satellite can compensate for such disadvantages, offering a new opportunity for the quantitative study of regional land WSC. The GRACE mission provides approximately monthly assessments of WSC based on measurements of the variation of the Earth's global gravity field, mainly due to land WSC, ice masses (e.g., polar ice sheets, alpine glaciers, and ice caps), and other geophysical signals (e.g., postglacial rebound and deformation caused by earthquakes) [23-25]. Interference signals in the GRACE data are caused by atmospheric and ocean-mass variations, which can be removed successfully using numerical simulations [26], and therefore, following the removal of such geophysical signals, the WSC can be determined. The GRACE satellite can monitor the water equivalent change of the ground to about $0.9 \mathrm{~cm}$ and that the precision can reach $1-1.5 \mathrm{~cm}[27,28]$. Some researchers have compared the results retrieved by GRACE with those calculated using global land-surface-process models. The two methods produce results that are similar in most areas, but there are also discrepancies related to difficulties in obtaining precise input data in some areas. WSC retrieved by GRACE can overcome such problems, and thus it can provide a reference for the improvement of the accuracy of global land-surface-process models [29-32]. GRACE data have been applied to monitoring soil moisture and/or groundwater depletion due to drought or irrigation [33-36] and to extract flux information from the water balance equation, such as evapotranspiration [37, 38] or river discharge [39-42]. In addition, WSC retrieved by GRACE has been used in cryospheric-related research on permafrost activities and WSC in the Arctic and Alaska, indicating that changes in the permafrost active layer might be an important reason behind the variation of WSC in these areas $[2,43]$. In China, researches focused on large areas, such as the Chinese continental region, Xinjiang, and the surrounding mountainous area [44-48]. Generally, these researches have involved regional quantitative descriptions of WSC and have established that different regions exhibit different variational features. However, a comprehensive study of permafrost WSC and of its causes in the Three-River Source Region of the TP has not been reported previously.

In this study, gravity information retrieved from GRACE satellite observations was used to derive monthly assessments of WSC during 2003-2010 in the Three-River Source Region (i.e., the source regions of the Yellow River, the Yangtze River, and the Lancang River). This investigation focused on the influence of permafrost on WSC, changes in WSC related to different types of permafrost, and further water balance changes of study area and subregions. This work will provide a baseline for water resource management in the region which includes ecological protection and development, reservoir operation, and design of hydraulic structures.

\section{Study Area}

The Three-River Source Region is located in the interior of the TP, encompassing parts of western Tibet and southern Qinghai province. It is the location of the headwaters of the Yangtze River, the Yellow River, and the Lancang River, lying between $31^{\circ} 06^{\prime}-35^{\circ} 42^{\prime} \mathrm{N}$ and $90^{\circ} 36^{\prime}-103^{\circ} 24^{\prime} \mathrm{E}$ (Figure 1). The entire study area is $30.2 \times 10^{4} \mathrm{~km}^{2}$ and it includes the subregions of the individual sources of the Yangtze River, the Yellow River, and the Lancang River, which cover $13.0 \times 10^{4}$, $11.8 \times 10^{4}$, and $5.4 \times 10^{4} \mathrm{~km}^{2}$, accounting for $43.2 \%, 39 \%$, and $17.8 \%$, respectively, of the total area. The Lancang River is source of the Mekong River. The annual rainfall of the region is $445 \mathrm{~mm}$ and the annual average temperature is $-1.45^{\circ} \mathrm{C}$ [13]. The annual average runoff within the study area is about $47.5 \times$ $10^{9} \mathrm{~m}^{3}$, of which the Yellow River, the Yangtze River, and the Lancang River account for $20.1 \times 10^{9}, 12.4 \times 10^{9}$, and $15.0 \times$ $10^{10} \mathrm{~m}^{3}$, respectively. There are four types of permafrost in the Three-River Source Region: continuous permafrost, seasonal permafrost, island permafrost, and patchy permafrost, which encompass areas of $16.2 \times 10^{4}, 12.0 \times 10^{4}, 1.1 \times 10^{4}$, and $0.9 \times$ $10^{4} \mathrm{~km}^{2}$, respectively (Figure 1).

\section{Materials and Methods}

3.1. Precipitation Data and Spatial Interpolation Method. Precipitation data from 2003 to 2010 were obtained from national meteorological stations within the study area (Table 1) and corrected for the influence of wind [51].

Furthermore, to improve the continuous spatial extent of precipitation measurements within the study area, the data were interpolated using Kriging with consideration of elevation [52]. This method uses precipitation and site elevation data to perform a linear regression. The spatial $P_{r}$ (the rasterized precipitation regressed by elevation) was calculated using the formula for linear regression, the residuals (regressed precipitation minus measured precipitation) were interpolated using the Kriging spatial interpolation method, and then the values of the spatial $P_{r}$ were added to the spatial residuals, providing the spatial distribution of precipitation:

$$
P_{\text {result }}=P_{r}+P_{\text {residual }} \text {, }
$$


TABLE 1: The distribution of national meteorological stations within the study area.

\begin{tabular}{lccc}
\hline Name & Elevation $(\mathrm{m})$ & Latitude $\left(^{\circ}\right)$ & Longitude $\left(^{\circ}\right)$ \\
\hline Nang Qian & 3643.7 & 32.2 & 96.5 \\
Za Duo & 4066.4 & 32.9 & 95.3 \\
Ban Ma & 8530.0 & 32.9 & 100.8 \\
Yu Shu & 3681.2 & 33.0 & 97.0 \\
Jiu Zhi & 3628.5 & 33.4 & 101.5 \\
Da Ri & 3967.5 & 33.8 & 99.7 \\
Qing Shui He & 4415.4 & 33.8 & 97.1 \\
Zhi Duo & 4179.0 & 33.9 & 95.6 \\
Qu Ma Lai & 4175.0 & 34.1 & 95.8 \\
Tuo Tuo He & 4533.1 & 34.2 & 92.4 \\
Zhong Xing Zhan & 4211.1 & 34.3 & 99.2 \\
Guo Luo & 3719.0 & 34.5 & 100.3 \\
He Nan & 8500.0 & 34.7 & 101.6 \\
Ma Duo & 4272.3 & 34.9 & 98.2 \\
Ze Ku & 3662.8 & 35.0 & 101.5 \\
Wu Dao Liang & 4612.2 & 35.2 & 93.1 \\
Tong De & 3289.4 & 35.3 & 100.7 \\
Xing Hai & 3323.2 & 35.6 & 99.9 \\
\hline
\end{tabular}

where $P_{\text {result }}$ is the spatial precipitation, $P_{r}$ is the rasterized precipitation regressed by elevation, and $P_{\text {residual }}$ is the spatial residual (units of precipitation: $\mathrm{mm}$ ).

3.2. Change of Precipitation. Precipitation is the main source of land surface water and changes in precipitation affect evaporation, runoff, and WSC. In this study, the change of precipitation was calculated using the following formula:

$$
P_{c}=P_{i}-P_{i-1},
$$

where $P_{c}$ is the change of precipitation, $P_{i}$ is the precipitation in month $i, P_{i-1}$ is the precipitation in the preceding month, and $i$ represents the month (from 1 to 12 ).

3.3. Retrieval Method for WSC Data. This study used Release05 (R5) Level-2 from the University of Texas Center for Space Research (http://www.csr.utexas.edu/grace/asdp.html). Because of the reference frame used in the determination of GRACE satellites gravity field, gravity field coefficients of degree 1 in RL05 were processed as zero. However, the degree 1 information could have significant impact on the recovery of surface mass variations. To improve the accuracy and precision in deriving WSC, the original gravitational coefficients of degree 1 in RL05 were replaced by calculated values [21]. RL05 data, with the same signals in RL04, has been improved with significant noise reduction. Given that the C20 coefficient measured by satellite laser ranging (SLR) is much better than that in RL05, C20 in RL05 was replaced with SLR C20 [36]. A decorrelation filter was applied to reduce the effects of noisy $\mathrm{N}-\mathrm{S}$ stripes in the monthly time-variable coefficients. Correlated noises (N-S stripes) were removed from coefficients for orders $(m)$ greater than 15 using a fifth-order polynomial, which was fitted as a function for each odd or even set for

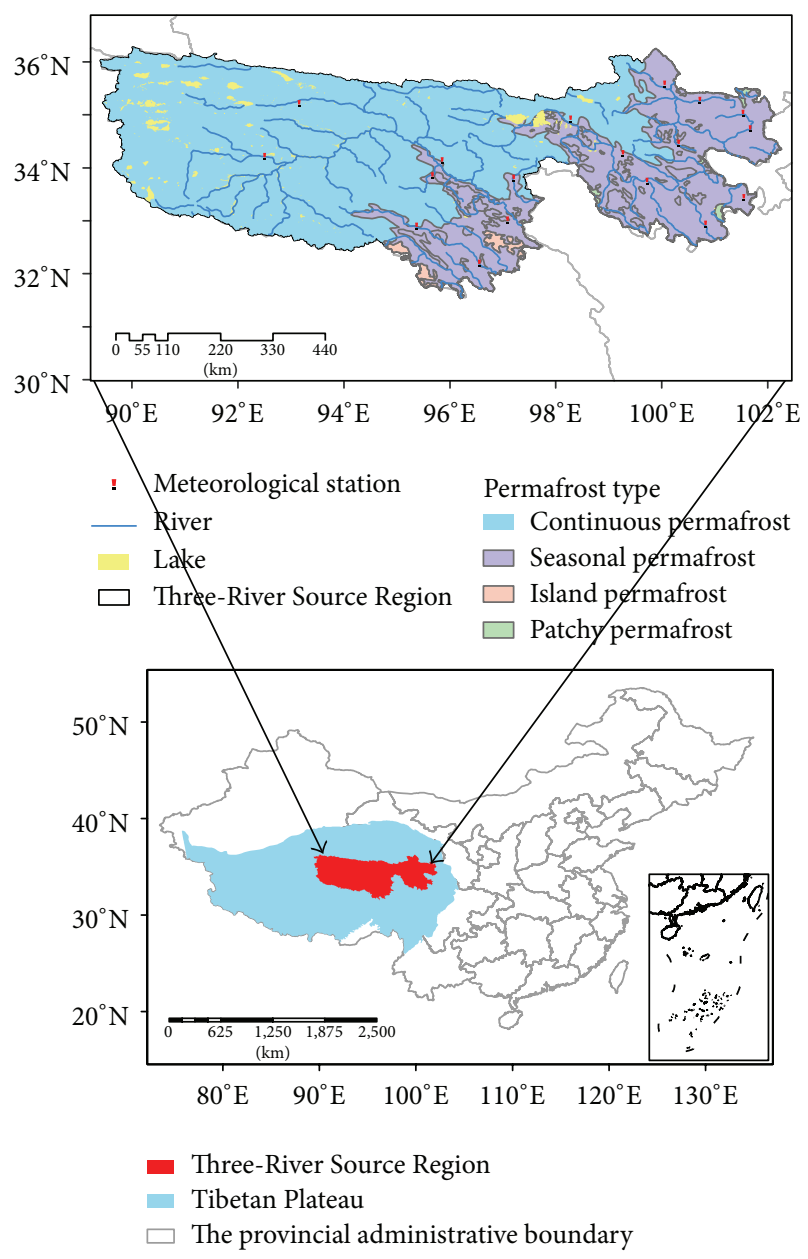

Figure 1: Location of the study area.

a given order [43]. These processed spherical harmonic coefficients were transformed into gridded data with 1-arcdegree spatial resolution, indicating the Earth's surface mass variations, which in most regions were caused mainly by the redistribution of water on continents or in oceans. The global grids comprised 1-arc-degree water equivalent mass change complete to degree and order 60. The GRACE R5 Level-3 (300 km Gauss-smoothing kernel) land and ocean monthly grids during 2003-2010 were combined to provide global coverage $[53,54]$. Glacial isostatic adjustment of solid mass flow within the Earth's mantle which was small in the study region [55]. The process of retrieving is given by

$$
\begin{gathered}
\Delta h(\phi, \lambda, t)=\frac{a_{e} \rho_{e}}{3 \rho_{w}} \sum_{l=0}^{40} \sum_{m=0}^{l} \frac{(2 l+1)}{1+k_{l}} W_{l} P_{l m} \sin (\phi) \\
\cdot\left[\Delta C_{l m}(t) \cos (m \lambda)+\Delta S_{l m}(t) \sin (m \lambda)\right], \\
W_{l}=\exp \left[\frac{\left(l r / a_{e}\right)^{2}}{4 \ln (2)}\right],
\end{gathered}
$$

where $P_{l m}$ are normalized Legendre polynomials, $\Delta C_{l m}(t)$ and $\Delta S_{l m}(t)$ are normalized time-varying Stokes spherical 
harmonic geopotential coefficients, $a_{e}$ is Earth's mean radius, $r$ is the spatial radius, $k_{l}$ are Love numbers, $\rho_{e}$ is Earth's mean density, $\rho_{w}$ is water density, $t$ is time, and $\phi$ and $\lambda$ are latitude and longitude, respectively.

3.4. Basin-Scale Water Balance. The basic elements of a basinal water cycle include precipitation, runoff, evaporation, and WSC. Actual evaporation $\left(\mathrm{ET}_{a}\right)$ is an important factor in studies of hydrology that is difficult to measure on regional or continental scales. Although ET can be estimated indirectly using remote sensing data based on empirical, energy balance, or physical models (e.g., the Penman-Monteith equation), recent remotely sensed $\mathrm{ET}_{a}$ estimations are far from satisfactory. Because ET is a complex process that is related to many variables, its estimation uncertainty based on remote sensing data brings errors to $\mathrm{ET}_{a}$ retrieval results. Based on the river-basin-scale terrestrial water balance, changes of regional ET can be estimated by combining WSC change from GRACE using observed precipitation $(P)$ and runoff data $(R)$. Within a closed area, changes in various elements of the water cycle determine the regional water cycle characteristics. The water balance equation was used to calculate actual evaporation. The basic equation of water balance is

$$
\mathrm{ET}_{a}=P-R \pm W
$$

where $\mathrm{ET}_{a}$ is actual evaporation, $P$ is precipitation, $R$ is runoff, and $W$ is the surplus of water storage of the watershed, when it is "-" it means the water storage is in a state of loss and when it is "+" it means more water stay in basin and the water storage is in a state of gain in basin. As changes in the water cycle are balanced over time, changes of the water balance factors $\left(\mathrm{ET}_{a}, P\right.$, and $\left.R\right)$ are also in a state of balance; thus, (5) can be expressed as

$$
\Delta \mathrm{ET}_{a}=\Delta P-\Delta R \pm \Delta W,
$$

where $\Delta \mathrm{ET}_{a}$ is the change of actual evaporation, $\Delta P$ is the change of precipitation, $\Delta R$ is the change of runoff, and $\Delta W$ is the WSC of the watershed which can be retrieved by GRACE.

3.5. WSC Cycle. To explore the extent and period of WSC within the study area quantitatively in different type of permafrost and find the regular pattern of WSC in permafrost, we calculated the WSC cycle by least squares method. Least squares method is a mathematical optimization technology; it does this by minimizing the error sum of squares of data to find the best matching function. To study the extent and period of WSC quantitatively within the study area, the least squares method was used to calculate the cycle and amplitude of the regional WSC in monthly data, the amplitude reflects the intensity of the water cycle, and the cycle reflects the period at a time:

$$
y(t)=A \cdot \sin \left[2 \pi \cdot \frac{(t-\varphi)}{\omega}\right],
$$

where $A$ is the amplitude, $\varphi$ is phase, and $\omega$ is the cycle. Amplitude represents the intensity of WSC and the cycle represents the length of WSC in the time series.

\section{Results and Discussion}

4.1. Temporal and Spatial Patterns of WSC and Precipitation over the Three-River Source Region. The WSC was retrieved from GRACE satellite data during 2003-2010 over the ThreeRiver Source Region, and the distributions of the average WSC and average change of precipitation, calculated using (1), (2) and (3), are shown in Figures 2(a) and 2(b), respectively. As can be seen, there was less change in the south compared with the north and considerably more change in the west than in the east. The range of precipitation was from -2.9 to $29.8 \mathrm{~mm}$ with its distribution decreasing from east to west. Precipitation has decreased in the source region of the Yangtze River and increased over most parts of the source region of the Yellow River and the Lancang River. There were differences between the spatial distributions of WSC and precipitation, which indicate that the distribution of WSC was not only influenced by precipitation but also affected by the type of permafrost of the underlying surface. The WSC was in a state of surplus in the source region of the Yangtze River with a maximum value of $247.4 \mathrm{~mm}$. This may be the highmountain glaciers which supplied the WSC within this region [56]. Furthermore, the source region of the Yangtze River comprises numerous and often quite large thaw ponds, lakes, and drained thaw-lake basins [57]. These lakes reside in the thick ice-rich continuous permafrost zone (Figure 1). Their development and growth are related to thermal processes at the ice-wedge intersections, permafrost thawing with subsidence of the ground surface, and increased thickness of the active layer [43]. Over time, small ponds merge into large lakes and some will drain when thermoerosion and bank undercutting cause a breach $[58,59]$. Beneath such lakes, a talik that was previously unfrozen soil develops into a closed talik [60]. The lateral and vertical extents of a talik depend on the internal structure of the permafrost and on the temperature regime at the ground surface. Eventually, the talik can become an open talik and serve as an aquifer, whereby lake water drains to become subsurface groundwater, which increases the groundwater storage within or in some cases below the permafrost. This indicated that surface water is being recruited for subsurface groundwater storage (including ice growth) and that the groundwater residence time is increasing. Additionally, groundwater storage is increasing because of increases in the numbers and areas of thaw bogs, ponds, and lakes. Independent research has indicated that lakes have been increasing in the continuous permafrost zone of the TP [57].

WSC was in a state of surplus in the northwest of the source region of the Yellow River from 2003 to 2010, which is an area of continuous permafrost. However, it was in a state of loss in the southeast of the source region of the Yellow River, which is an area of seasonal permafrost and patchy permafrost, although precipitation has increased in this area (Figure 1). The WSC was in a state of loss in the source region of the Lancang River (minimum value; $-29.3 \mathrm{~mm}$ ), where the main types of permafrost are seasonal and island permafrost and where precipitation has decreased. Because of rising temperatures in the region over recent decades [61], some of the ground ice of seasonal, patchy, and island permafrost areas 


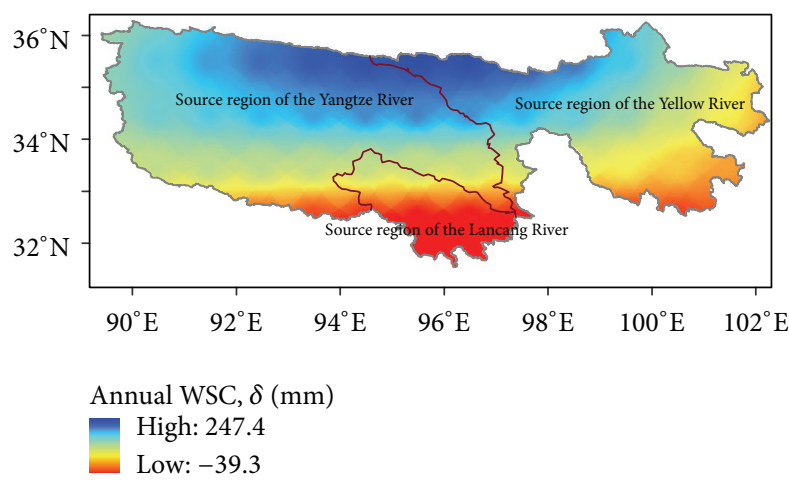

(a)

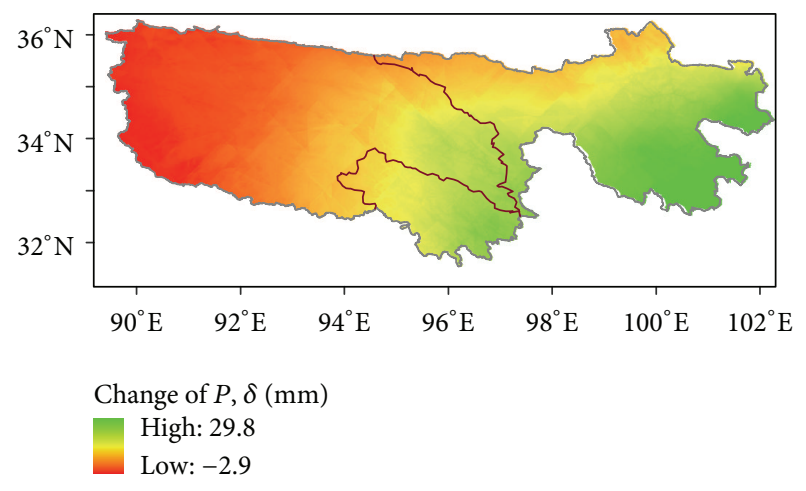

(b)

FIGURE 2: Spatiotemporal patterns of average annual (a) water storage change (WSC) and (b) precipitation $(P)$ over the Three-River Source Region during 2003-2010.

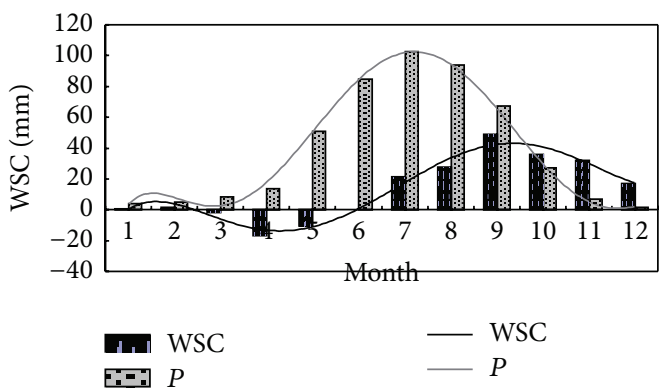

(a)

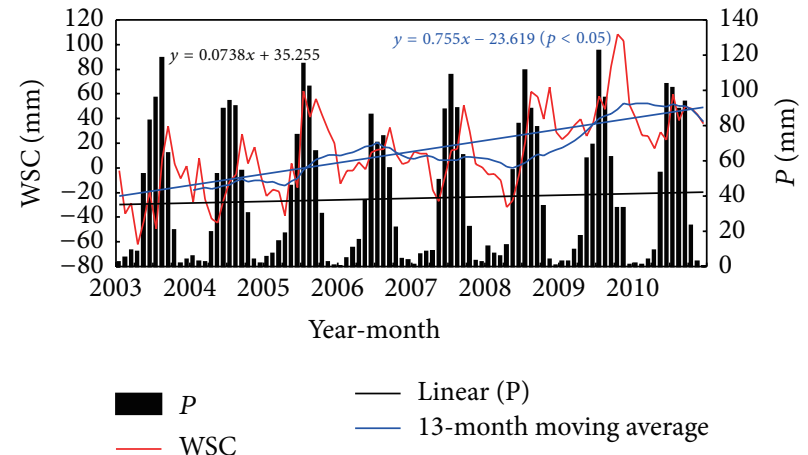

(b)

FIgURE 3: (a) Annual distributions of WSC and (b) time series of water storage change (WSC) and precipitation $(P)$ over the Three-River Source Region during 2003-2010.

has melted, and thus the WSC was in a state of loss. Through the above analysis, it can be suggested that the spatial distribution of WSC is linked to the type of permafrost in the Three-River Source Region.

WSC and precipitation have obvious seasonal variations, but the process of WSC has a certain lag compared with the process of precipitation, which indicates that permafrost plays a decisive role in the formation of cold groundwater, transport processes, and the pattern of distribution of groundwater and its pathways in the Three-River Source Region. The study area is located in the interior of the TP where sources of water vapor depend mainly on the zonal westerly circulation and the Indian Ocean monsoon $[62,63]$. Rainfall in this area was concentrated mainly from May to October, when the WSC generally increases and the peak value appears. The maximum value of average monthly precipitation during $2003-2010$ was $102.5 \mathrm{~mm}$ in July (Figure 3(b)). The gain of WSC was concentrated mainly during the months from July to December, which begins during the period of maximum precipitation; the maximum value of average monthly WSC was $48.7 \mathrm{~mm}$ in September. Precipitation was relatively small in January and February, but runoff was also low in winter. This means there is less water to flow out of the study area, and thus WSC displays a weak surplus. Precipitation was also low during March to June, but the runoff of the Yangtze River, the Yellow River, and the Lancang River was recharged from the Three-River Source Region, which leads to a state of loss of WSC; the minimum value of average monthly WSC is $-16.6 \mathrm{~mm}$ in April. In the Three-River Source Region, there was an obvious annual increase in WSC during 2003-2010; the average rate of increase was about $9.06 \pm 0.01 \mathrm{~mm} / \mathrm{a}$, and the total increase in the quantity of water was about $21.89 \pm 0.02 \times 10^{9} \mathrm{~m}^{3}$.

The amplitude of variation of WSC across the study area was -62.2 to $108.4 \mathrm{~mm}$. This means that the maximum value of increased water was about $108.4 \mathrm{~mm}$ equivalent water height and the minimum value was $-62.2 \mathrm{~mm}$ equivalent water height. Monthly precipitation was between 0.2 and $122.5 \mathrm{~mm}$. Generally, there was little variation in annual precipitation in the Three-River Source Region during 20032010 (Figure 3(b)), but WSC showed a significant upward trend. And the characteristics of the variation of precipitation had a dominant effect on WSC in the time series.

4.2. Monthly Average WSC during 2003-2010. The distributions of monthly average WSC indicate differences during the years for which it was retrieved by GRACE (Figure 4). It can be seen that WSC is in a state of loss in the south of 

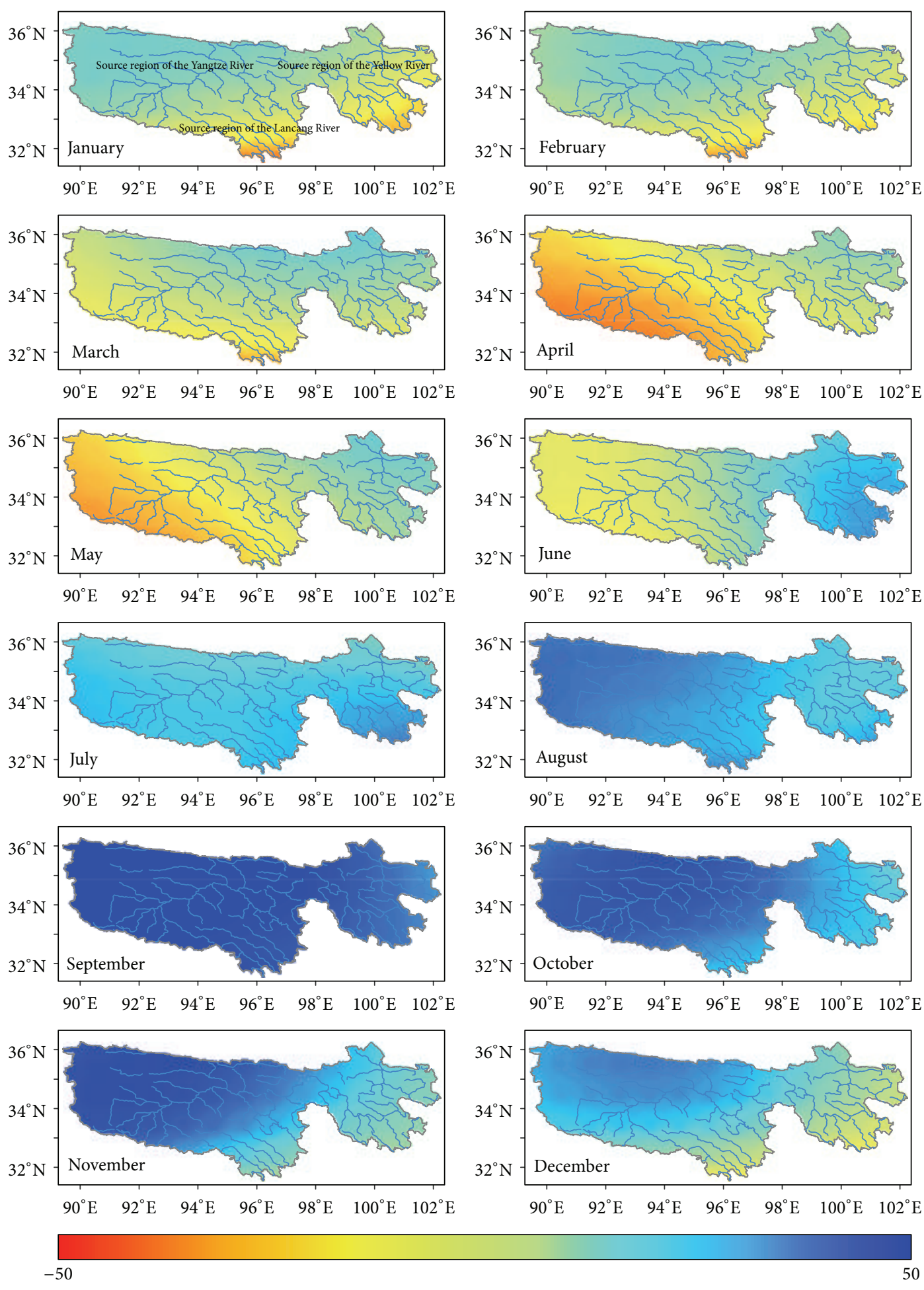

$(\mathrm{mm})$

FIGURE 4: Monthly averages of water storage change during 2003-2010.

the Three-River Source Region (source regions of the Yellow River and the Lancang River) from January to March and in December; the average loss is about $-20 \mathrm{~mm}$. However, the WSC is in a state of gain in the north of the Three-River Source Region in January and February; the average gain is about $15 \mathrm{~mm}$, but it is greater in December (about $31 \mathrm{~mm}$ ) than in January and February. Runoff in the source regions of the Yangtze River, the Yellow River, and the Lancang River increases from April to June when precipitation is low, which leads to a state of loss of WSC. The patterns of spatial 

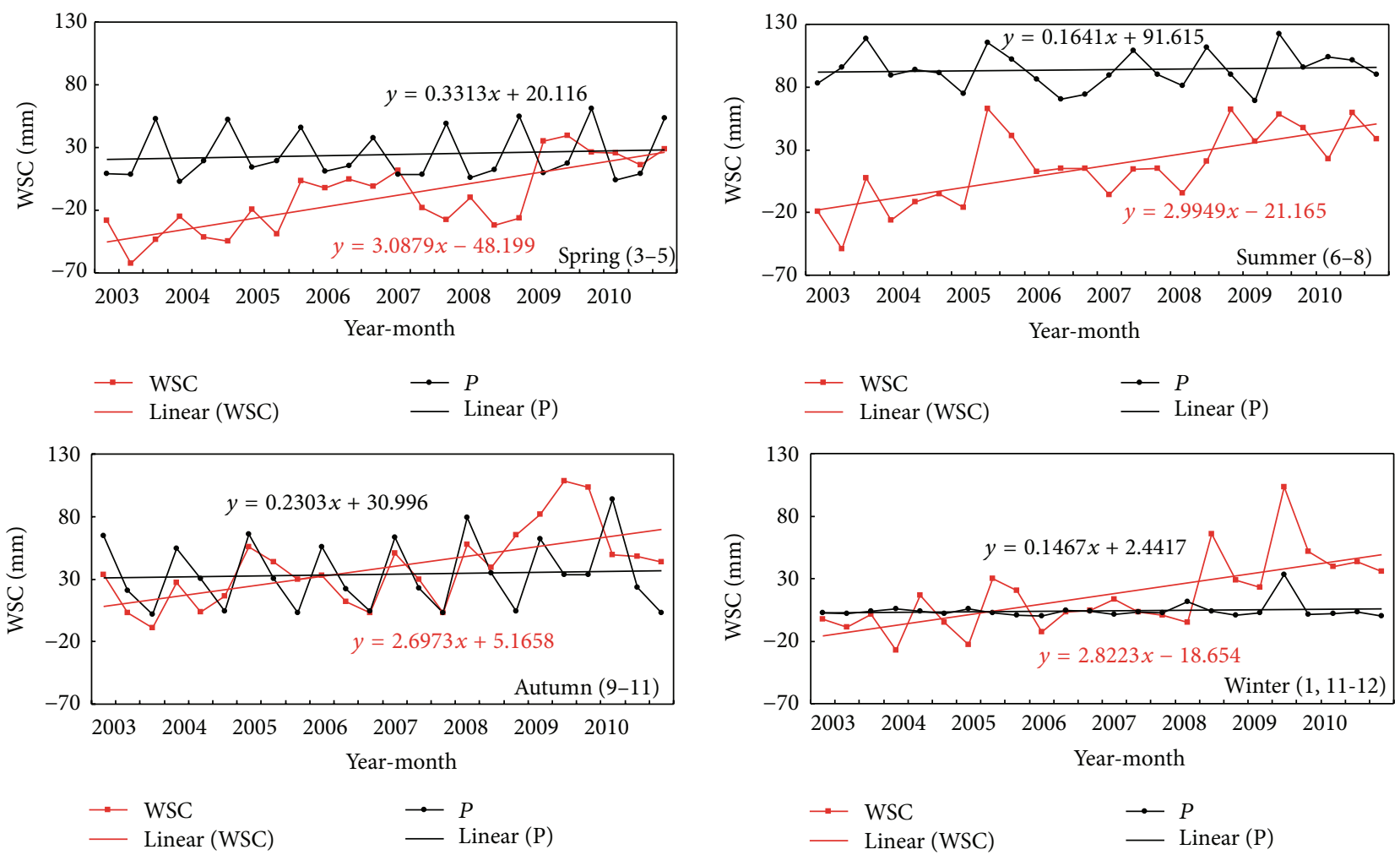

FIGURE 5: Seasonal processes of water storage change (WSC) and precipitation (P) in the Three-River Source Region during $2003-2010$.

distribution of WSC show a state of gain in the east and loss in the west; the largest area of loss occurs in April. The loss of WSC is most serious in the southwest in April and May, when the average value of loss reaches $33 \mathrm{~mm}$, while there is a weak surplus of WSC in the east of about $10 \mathrm{~mm}$. The areas of loss and gain of WSC comprise about half the total area in June. The westerly circulation and the East Asian and Indian monsoon are the main sources of water vapor in the Three-River Source Region, bringing large quantities of precipitation in summer [64]. The occurrence of the rainy season and glacier meltwater supply the WSC from July, leading to the state of gain of WSC from July to November. The largest surplus of WSC occurs in September.

\subsection{Seasonal Variation of WSC and Precipitation during 2003-} 2010. Figure 5 shows the seasonal WSC and precipitation in the Three-River Source Region during 2003-2010. It can be seen that precipitation showed a slight upward trend over the four seasons; the largest increase was in spring, followed by autumn, summer, and winter. WSC showed a significant increase in trend over the four seasons; the rates of increase were $9.26 \pm 0.71,8.98 \pm 0.39,8.09 \pm 6.20$, and $8.45 \pm 2.48 \mathrm{~mm} / \mathrm{a}$ in spring, summer, autumn, and winter, respectively. The fastest growth of WSC was in spring and the slowest increase was in autumn. The process of WSC was more consistent with the process of precipitation in spring and autumn, which indicates that WSC was controlled largely by precipitation during these seasons. The variations of the values of WSC were significantly lower than the values of precipitation in spring and summer. WSC in spring showed a value of loss before 2009 and then a surplus in 2009 and 2010 largely because precipitation is higher in the winters of 2008 and 2009 than in previous years. The WSC shows losses in the summers of 2004 and 2005 and gains during 2005-2010. Precipitation fluctuates little in winter in the Three-River Source Region during 2003-2010, but the fluctuation of WSC was relatively large because most of values of WSC show a loss in January, while they show surpluses in November and December.

4.4. Processes of WSC and Precipitation in Different Types of Permafrost in the Three-River Source Region. Regionalized time series of WSC retrieved by GRACE and precipitation show monthly water equivalent mass variations within the different types of permafrost (continuous, seasonal, island, and patchy permafrost) in the Three-River Source Region (Figure 6). The gradient and uncertainties of water equivalent mass change in units of thickness $(\mathrm{mm})$, rates of change, and the total WSC during 2003-2010 in volume water equivalent cubic meters $\left(\mathrm{m}^{3}\right)$ are given in Table 2 . It can be seen that WSC exhibits strong seasonal fluctuations, but changes in precipitation were not obvious for the different types of permafrost. WSC of the four types of permafrost shows an increasing trend of growth. The fastest rate of growth was associated with the continuous permafrost, while the lowest occurs for the island permafrost. The greatest amount of water increase occurs for the continuous permafrost, followed by seasonal frozen soil, patchy permafrost, and island permafrost (Table 2). Based on the analysis above, for cases 
TABLE 2: Amount of water storage change (WSC) over different types of permafrost in the Three-River Source Region during $2003-2010$.

\begin{tabular}{lcc}
\hline Region & Rate of change $(\mathrm{mm} / \mathrm{a})(p<0.05)$ & $2003-2010 \mathrm{WSC}^{\left(10^{9} \mathrm{~m}^{3}\right)}$ \\
\hline Continuous permafrost & $10.29 \pm 0.37$ & $13.94 \pm 0.48$ \\
Seasonal permafrost & $6.67 \pm 0.45$ & $6.90 \pm 0.43$ \\
Patchy permafrost & $7.81 \pm 0.38$ & $0.61 \pm 0.03$ \\
Island permafrost & $4.43 \pm 0.71$ & $0.44 \pm 0.06$ \\
\hline
\end{tabular}
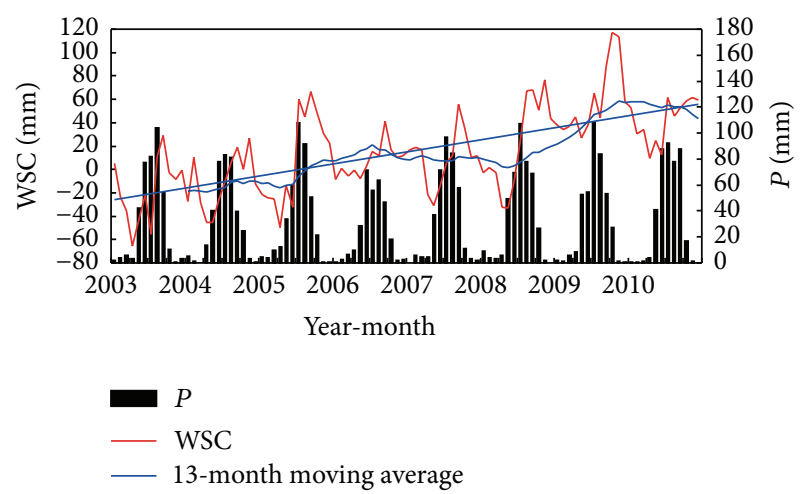

(a)
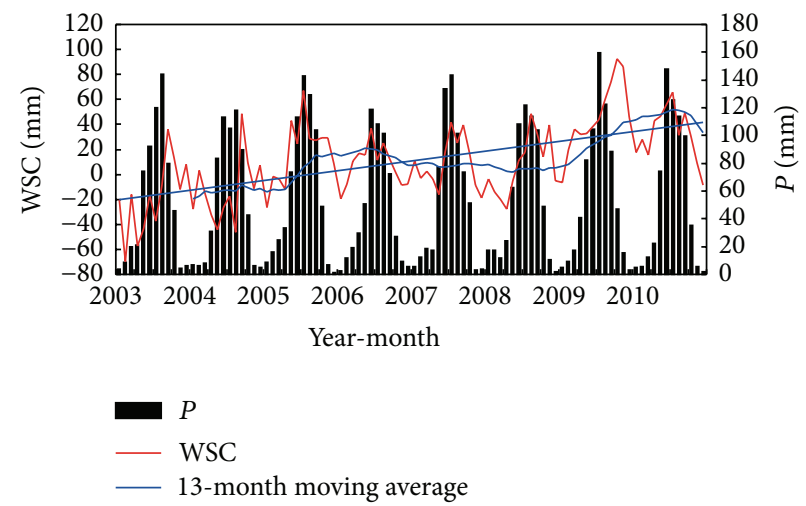

(c)
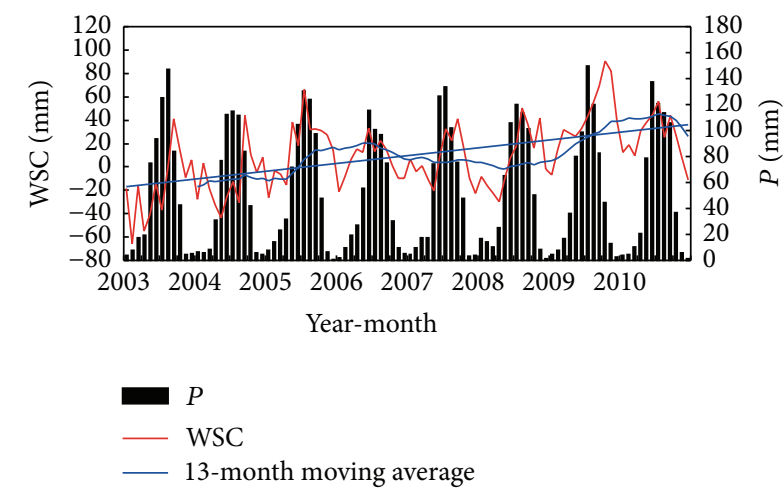

(b)

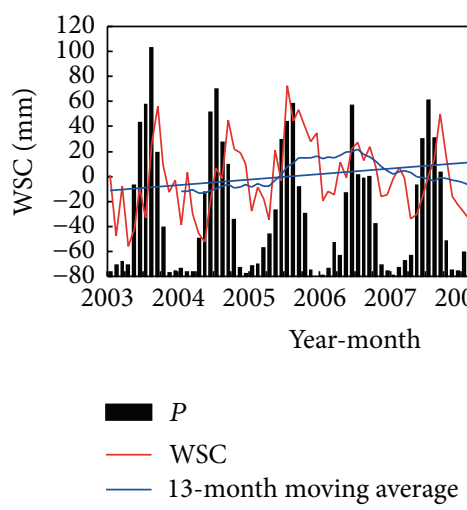

(d)

Figure 6: Time series of water storage change (WSC) and precipitation (P) over different types of permafrost during 2003-2010: (a) continuous permafrost, (b) seasonal permafrost, (c) patchy permafrost, and (d) island permafrost.

with little change in precipitation, the different types of permafrost will increase the regional WSC but to differing degrees.

The trends of WSC retrieved by GRACE are in line with normal patterns, and thus the cycles were analyzed using (6). Table 3 shows that the precipitation was 384.7, 622.2, 640.2 , and $571.8 \mathrm{~mm}$ for the continuous permafrost, seasonal permafrost, patchy permafrost, and island permafrost, respectively. The amplitude of the land surface-water resource reflects the intensity of the hydrological cycle, and the cycle represents the duration of WSC. As can be seen from Table 2, the smallest intensity of WSC was $23.8 \mathrm{~mm}$ in the seasonal permafrost. The largest amplitude was $78.9 \mathrm{~mm}$ in the continuous permafrost, but it has the lowest precipitation. Both the amplitude and the cycle were higher for this zone than the other areas, indicating that the change of water resource in this area had greater complexity and uncertainty and that although the WSC of the area has increased overall, the distribution of WSC is unequal; that is, there was more water stored in the continuous permafrost. The largest cycle of WSC occurred in the continuous permafrost (about 103.3 months) and the smallest cycle of WSC occurred in the island permafrost (about 12.0 months). This indicates that the existence of continuous permafrost reduces the speed of the water cycle and leads to an increase of WSC. Whether on temporal or spatial scales, the distribution of WSC in the Three-River Source Region is shown to be heterogeneous.

4.5. Changes of Water Balance in the Subregions of the ThreeRiver Source Region. The Three-River Source Region comprises the headwaters of the Yangtze River, the Yellow River, and the Lancang River (Figure 1). The WSC and precipitation during 2003-2010 in the three subregions of the Three-River Source Region are presented in Figure 7. It can be seen that the regional WSC exhibits strong seasonal fluctuations, but changes in precipitation are not obvious. The trend of increase 
TABLE 3: Period of water storage change over different types of permafrost in the Three-River Source Region during 2003-2010.

\begin{tabular}{lccc}
\hline Region & Amplitude $(\mathrm{mm})$ & Period (month) & Annual precipitation $(\mathrm{mm})$ \\
\hline Continuous permafrost & 78.9 & 103.3 & 384.7 \\
Seasonal permafrost & 23.8 & 19.0 & 622.2 \\
Patchy permafrost & 24.5 & 20.2 & 640.2 \\
Island permafrost & 29.0 & 12.0 & 571.8 \\
\hline
\end{tabular}

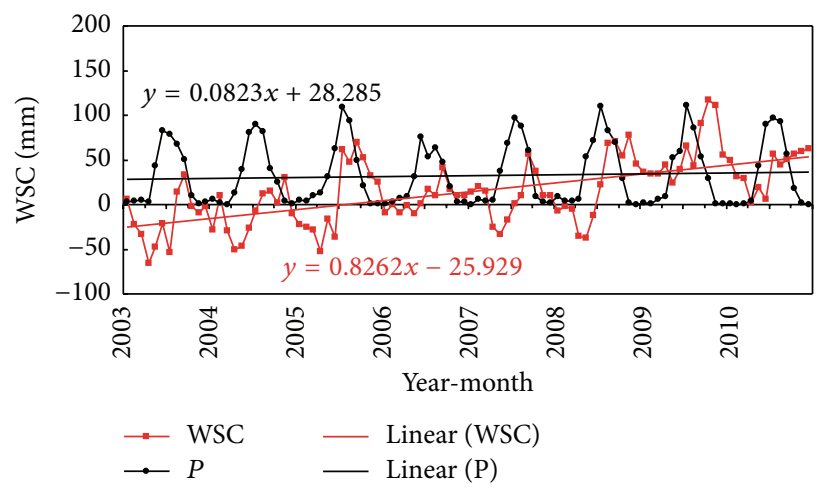

(a)

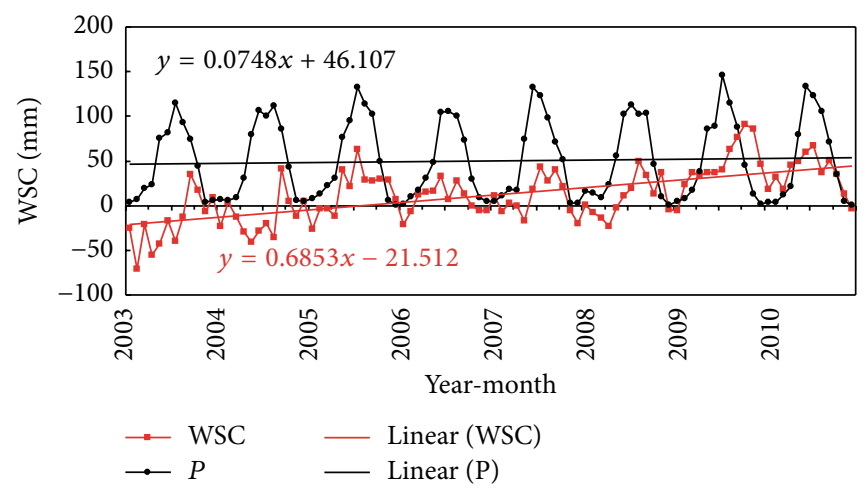

(b)

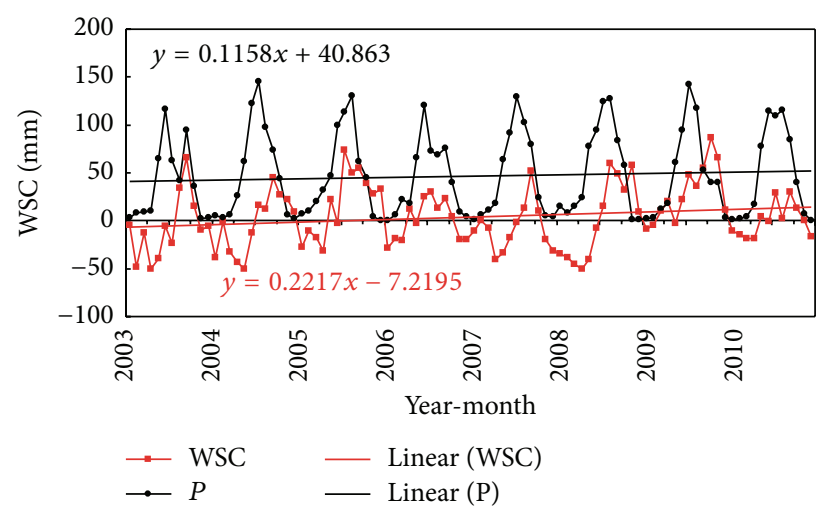

(c)

Figure 7: Time series of water storage change (WSC) and precipitation $(P)$ over the subregions of the Three-River Source Region during 2003-2010: (a) the Yangtze River, (b) the Yellow River, (c) the Lancang River.

of WSC was greatest in the source region of the Yangtze River and lowest in the source region of the Lancang River. The cycles of the three subregions were analyzed using (6). It can be seen from Table 4 that the source region of the Yangtze River, which is largely continuous permafrost, has the largest amplitude and longest cycle but lowest precipitation $(387.3 \mathrm{~mm})$. The shortest water cycle occurs in the source region of the Lancang River, which is largely seasonal frozen soil and island permafrost. The lowest amplitude occurs in the source region of the Yellow River, which is largely seasonal frozen soil and a little patchy permafrost and continuous permafrost.

The changes of water balance in the Three-River Source Region and its three subregions during 2003-2010 were analyzed and the results are presented in Tables 5 and 6 . Precipitation within the study area shows different degrees of increasing trend. The fastest rate of increase was $1.70 \mathrm{~mm} / \mathrm{a}$ in the source region of the Lancang River, which was equivalent to a water volume of $0.73 \times 10^{9} \mathrm{~m}^{3}$. The increases in the source regions of the Yangtze River and the Yellow River were also considerable with rates of 1.19 and $1.24 \mathrm{~mm} / \mathrm{a}$, respectively. The rate of increase in precipitation was about $0.89 \mathrm{~mm} / \mathrm{a}$ across the Three-River Source Region. The trends of runoff also showed differences between the different regions. The runoff in the source region of the Yangtze River showed a slightly increasing trend over recent decades $(0.01 \mathrm{~mm} / \mathrm{a})$, equivalent to a water volume of $0.04 \times 10^{9} \mathrm{~m}^{3}$; however, it showed a slightly decreasing trend in the source region of the Yellow River $(-0.01 \mathrm{~mm} / \mathrm{a})$. Because of the lack of runoff data in the source region of the Lancang River, the runoff was calculated according to the water balance (i.e., rate of runoff; $-0.82 \mathrm{~mm} / \mathrm{a}$ ) and determined to be equivalent to a water volume of about $-0.36 \times 10^{9} \mathrm{~m}^{3}$. The runoff of the Three-River Source Region showed a decline of about $-0.59 \mathrm{~mm} / \mathrm{a}$, which is equivalent to a reduction in water volume of about $1.43 \times$ $10^{9} \mathrm{~m}^{3}$. 
TABLE 4: Period of water storage change over the subregions of the Three-River Source Region during 2003-2010.

\begin{tabular}{lccc}
\hline Region & Amplitude $(\mathrm{mm})$ & Period (month) & Annual precipitation $(\mathrm{mm})$ \\
\hline Source region of the Yangtze River & 57.0 & 67.6 & 387.3 \\
Source region of the Yellow River & 24.8 & 21.0 & 596.8 \\
Source region of the Lancang River & 31.5 & 12.0 & 557.8 \\
Three-River Source Region & 29.9 & 32.5 & 466.0 \\
\hline
\end{tabular}

TABLE 5: Average rates of water thickness change in the subregions of the Three-River Source Region.

\begin{tabular}{|c|c|c|c|c|}
\hline Region & $\Delta P(\mathrm{~mm} / \mathrm{a})$ & $\Delta R(\mathrm{~mm} / \mathrm{a})$ & $\Delta W(\mathrm{WSC})(\mathrm{mm} / \mathrm{a})$ & $\Delta E(\mathrm{~mm} / \mathrm{a})$ \\
\hline Source region of the Yangtze River & +1.19 & $+0.01[49]$ & +11.06 & -9.86 \\
\hline Source region of the Yellow River & +1.24 & $-0.01[50]$ & +9.28 & -8.03 \\
\hline Source region of the Lancang River & +1.70 & -0.82 & +3.52 & -1.00 \\
\hline Three-River Source Region & +0.89 & $-0.59[50]$ & +9.06 & -7.58 \\
\hline
\end{tabular}

TABLE 6: Changes of volume in subregion of Three-River Source Region.

\begin{tabular}{|c|c|c|c|c|}
\hline Region & $\Delta P\left(10^{9} \mathrm{~m}^{3}\right)$ & $\Delta R\left(10^{9} \mathrm{~m}^{3}\right)$ & $\Delta W($ WSC $)\left(10^{9} \mathrm{~m}^{3}\right)$ & $\Delta E\left(10^{9} \mathrm{~m}^{3}\right)$ \\
\hline Source region of the Yangtze River & +1.25 & +0.04 & +11.51 & -10.30 \\
\hline Source region of the Yellow River & +1.18 & -0.10 & +8.86 & -7.58 \\
\hline Source region of the Lancang River & +0.73 & -0.36 & +1.52 & -0.43 \\
\hline Three-River Source Region & +0.89 & -1.43 & +21.89 & -18.31 \\
\hline
\end{tabular}

The changes of water balance in the Three-River Source Region and its subregions can be calculated using (4) and (5). The rates and volumes of $\Delta P, \Delta R, \Delta W$, and $\Delta E$ in the headwaters of the Yangtze River, the Yellow River, and the Lancang River are given in Tables 4 and 5. The trends of change of evaporation $(\Delta E)$ in the Three-River Source Region and its subregions showed reductions in the magnitudes of water equivalent that decreased in Three-River Source Region and its subregions. Based on the Penman-Monteith equation, Cheng and $\mathrm{Qu}[61]$ indicated that evaporation has decreased in the source region of the Yellow River since the beginning of the 21st century. Furthermore, related studies have indicated that climate warming leads to the degradation of permafrost that can change the cycle of the water balance and inhibit evaporation $[65,66]$. The trend of $\Delta E$, although of similar magnitude, was of the opposite sign (decrease) relative to the trend determined using GRACE (increase). The decrease of $\Delta E$ in the source region of the Yangtze River is greatest at $-9.86 \mathrm{~mm} / \mathrm{a}\left(-10.30 \times 10^{9} \mathrm{~m}^{3}\right)$ and least in the source region of the Lancang River at $-1.00 \mathrm{~mm} / \mathrm{a}\left(-0.43 \times 10^{9} \mathrm{~m}^{3}\right)$.

The GRACE trends indicated that during 2003-2010, the source region of the Yangtze River had the largest water equivalent mass gain of $11.06 \mathrm{~mm} / \mathrm{a}\left(11.51 \times 10^{9} \mathrm{~m}^{3}\right)$ and that the source region of the Lancang River had the least water equivalent mass gain of $3.52 \mathrm{~mm} / \mathrm{a}\left(1.52 \times 10^{9} \mathrm{~m}^{3}\right)$. The source region of the Yellow River showed a mass gain of $9.28 \mathrm{~mm} / \mathrm{a}$ $\left(8.86 \times 10^{9} \mathrm{~m}^{3}\right)$. The rate of WSC in the Three-River Source Region is $9.06 \mathrm{~mm} / \mathrm{a}$. In all cases, the precipitation trends were clearly lower than those derived from GRACE. This suggests that precipitation is not the dominant component of the increase in the GRACE water mass trends of the Three-River Source Region. The changes in the water balance of the study area were mainly related to changes of WSC and evaporation that are attributable to the different types of permafrost.

\section{Conclusions}

The WSC in the Three-River Source Region was retrieved using GRACE data from 2003 to 2010. The total amount of WSC was calculated, analyzed, and discussed based on four types of permafrost (continuous, seasonal, island, and patchy permafrost permafrost). The greatest rate of increase of WSC was $10.29 \pm 0.37 \mathrm{~mm} / \mathrm{a}\left(13.94 \pm 0.48 \times 10^{9} \mathrm{~m}^{3}\right)$ for continuous permafrost. In cases of little change in precipitation, the different types of permafrost increased the regional WSC but to differing degrees. The retrieved results reflect the seasonal change, interannual and seasonal variation, and spatial distribution of the total water resource within the study area. WSC was linked to the development of new predominately closed and possibly open taliks in the continuous permafrost zone under large thaw lakes.

Permafrost plays an important role in the water cycle, and the increase and thickening of the active layer can lead to greater infiltration of surface water into the groundwater, which can result in increased water storage in the regional water balance. In the Three-River Source Region, the annual WSC increased obviously during 2003-2010 with an average rate of increase of about $9.06 \pm 0.01 \mathrm{~mm} / \mathrm{a}$. The total increase was equivalent to a water volume of $21.89 \pm 0.02 \times 10^{9} \mathrm{~m}^{3}$.

The study area encompasses the principal regions of glaciers and permafrost of the TP, which have an effect on the annual regional differences of WSC. WSC was influenced by precipitation in the time series, but there were inconsistencies in the spatial distribution. Seasonal changes of WSC were 
clear, but the seasonal differences, cycles, and annual magnitudes of change reflect the imbalance and heterogeneous nature of the water resource distribution in the Three-River Source Region. Continuous permafrost has the largest amplitude and longest cycle even though the precipitation is lowest.

According to the water balance, the trends of water factors $(\Delta P, \Delta R, \Delta W$, and $\Delta E$ ) in the Three-River Source Region and subregions (source regions of the Yangtze River, the Yellow River, and the Lancang River) had differences. The changes in precipitation and runoff were small in short time but WSC $(\Delta W)$ and evaporation $(\Delta E)$ changed significantly; the WSC increased and evaporation decreased during 2003-2010. The rate of decrease of evaporation was $-7.58 \mathrm{~mm} / \mathrm{a}$, which is $-18.31 \times 10^{9} \mathrm{~m}^{3}$. In cases of little precipitation and runoff, the increase of WSC was significant, which caused a decrease in evaporation from the permafrost.

\section{Conflict of Interests}

The authors declare no conflict of interests regarding the publication of this paper.

\section{Acknowledgments}

This study was supported by the National Key Program for Developing Basic Sciences (no. 2013CBA01806) in China, the Key of Chinese Academy of Sciences (KJZD-EWG03-04), National Natural Science Foundation of China (41501073, 41121001), China Postdoctoral Science Foundation (2015M580893), and the Foundation for Young Talents in Cold and Arid Regions Environmental and Engineering Research Institute of CAS (no. Y451191001).

\section{References}

[1] R. R. Muskett and V. E. Romanovsky, "Groundwater storage changes in arctic permafrost watersheds from GRACE and in situ measurements," Environmental Research Letters, vol. 4, no. 4, Article ID 045009, pp. 940-941, 2009.

[2] T. Zhang, R. G. Barry, K. Knowles, J. A. Heginbottom, and J. Brown, "Statistics and characteristics of permafrost and ground-ice distribution in the Northern Hemisphere," Polar Geography, vol. 23, no. 2, pp. 132-154, 2008.

[3] G. X. Wang, H. Hu, and T. B. Li, "The influence of freezethaw cycles of active soil layer on surface runoff in a permafrost watershed," Journal of Hydrology, vol. 375, no. 3-4, pp. 438-449, 2009.

[4] G. D. Cheng and H. J. Jin, "Groundwater in the permafrost regions on the Qinghai-Tibet Plateau and it changes," Hydrogeology \& Engineering Geology, vol. 40, no. 1, pp. 1-10, 2013.

[5] Y. Zhang, W. Chen, and D. W. Riseborough, "Transient projections of permafrost distribution in Canada during the 21st century under scenarios of climate change," Global and Planetary Change, vol. 60, no. 3-4, pp. 443-456, 2008.

[6] V. E. Romanovsky and T. E. Osterkamp, "Thawing of the active layer on the coastal plain of the Alaskan arctic," Permafrost and Periglacial Processes, vol. 8, no. 1, pp. 1-22, 1997.

[7] R. Reginald Muskett and V. E. Romanovsky, "Groundwater storage changes in arctic permafrost watersheds from GRACE and in situ measurements," Environmental Research Letters, vol. 4, no. 4, Article ID 045009, 2009.
[8] J. P. Yang, Y. J. Ding, and R. S. Chen, "Climatic causes of ecological and environmental variations in the source regions of the Yangtze and Yellow Rivers of China," Environmental Geology, vol. 53, no. 1, pp. 113-121, 2007.

[9] G. Wang, Y. Li, Y. Wang, and Y. Shen, "Impacts of alpine ecosystem and climatic changes on surface runoff in the source region of Yangtze River," Journal of Glaciology and Geocryology, vol. 29, no. 2, pp. 159-168, 2007.

[10] C. W. Xie, Y. J. Ding, S. Y. Liu, and G. X. Wang, “Comparison analysis of runoff change in the source regions of the Yangtze and Yellow River," Journal of Glaciology and Geocryology, vol. 25, no. 4, pp. 414-422, 2003.

[11] D. White, L. Hinzman, L. Alessa et al., "The arctic freshwater system: changes and impacts," Journal of Geophysical Research Biogeosciences, vol. 112, no. G04S54, pp. 310-317, 2007.

[12] M. K. Woo, "Northern hydrology in Canada's cold environments," in Regional Hydrological Response to Climate Change, vol. 38 of The GeoJournal Library, pp. 73-86, Springer, 1996.

[13] S. F. Zhang, D. Hua, X. J. Meng, and Y. Y. Zhang, "Climate change and its driving effect on the runoff in the 'three-river headwaters' region," Journal of Geographical Sciences, vol. 21, no. 6, pp. 963-978, 2011.

[14] L. Daofeng, T. Ying, L. Changming, and H. Fanghua, "Impact of land-cover and climate changes on runoff of the source regions of the Yellow River," Journal of Geographical Sciences, vol. 14, no. 3, pp. 330-338, 2004.

[15] L. Lin, F.-X. Li, A.-H. Guo, and X.-D. Zhu, "Study on the climate change trend and its catastrophe over 'sanjiangyuan' region in recent 43 years," Journal of Natural Resources, vol. 21, no. 1, pp. 79-85, 2006.

[16] X. H. Shi, N. S. Qin, Q. C. Wang et al., "Analysis on runoff variation characteristics and influencing factors in the upper Yellow River," Journal of Desert Research, vol. 27, no. 4, pp. 690-697, 2007.

[17] S. Zhang, S. Jia, C. Liu, W. Cao, F. Hao, and J. Liu, "Study on the changes of water cycle and its impacts in the source region of the Yellow River," Science in China, vol. 47, supplement 1, pp. 142-151, 2004.

[18] L. Li, Q. C. Wang, G. S. Zhang, Y. Fu, and L. D. Yan, "The influence of climate change on surface water in the upper Yellow River," Acta Geographica Sinica, vol. 59, no. 5, pp. 716-722, 2004.

[19] X. H. Shi, N. S. Qin, Q. C. Wang et al., "Analysis on runoff variation characteristics and influencing factors in the upper Yellow River," Journal of Desert Research, vol. 27, no. 4, pp. 690697, 2007.

[20] X. H. Shi, N. S. Qin, and W. J. Xu, “The variations characteristic of the runoff in the source regions of the Yangtze River from 1956 to 2004," Journal of Mountain Science, vol. 25, no. 5, pp. 513-523, 2007.

[21] G. Strassberg, B. R. Scanlon, and D. Chambers, "Evaluation of groundwater storage monitoring with the GRACE satellite: case study of the High Plains aquifer, central United States," Water Resources Research, vol. 45, no. 5, pp. 195-211, 2009.

[22] T. Shah, D. Molden, R. Sakthivadivel, and D. Seckler, The Global Groundwater Situation: Overview of Opportunities and Challenges, General Information, International Water Management Institute, Colombo, Sri Lanka, 2000.

[23] J. Wahr, M. Molenaar, and F. Bryan, "Time variability of the Earth's gravity field: hydrological and oceanic effects and their possible detection using GRACE," Journal of Geophysical Research: Solid Earth, vol. 103, no. 12, Article ID 98JB02844, pp. 30205-30229, 1998. 
[24] B. D. Tapley, S. Bettadpur, J. C. Ries, P. F. Thompson, and M. M. Watkins, "GRACE measurements of mass variability in the Earth system," Science, vol. 305, no. 5683, pp. 503-505, 2004.

[25] M. Xu, S. C. Kang, and J. Z. Li, "Evaluation of water storage change of inland cryosphere in Northwestern China," Advances in Meteorology, vol. 2015, Article ID 681634, 12 pages, 2015.

[26] S. Bettadpur, GRACE Level-2 Gravity Field Product User Handbook, Center for Space Research, The University of Texas at Austin, Austin, Tex, USA, 2003.

[27] O. B. Andersen and J. Hinderer, "Global inter-annual gravity changes from GRACE: early results," Geophysical Research Letters, vol. 32, no. 1, pp. 1-4, 2005.

[28] G. Ramillien, A. Cazenave, and O. Brunau, "Global time variations of hydrological signals from GRACE satellite gravimetry," Geophysical Journal International, vol. 158, no. 3, pp. 813-826, 2004.

[29] A. Guntner, "Improvement of global hydrological models using GRACE data," Surveys in Geophysics, vol. 29, no. 4-5, pp. 375397, 2008.

[30] D. D. Rowlands, S. B. Luthcke, S. M. Klosko et al., "Resolving mass flux at high spatial and temporal resolution using GRACE intersatellite measurements," Geophysical Research Letters, vol. 32, no. 4, Article ID L4310, 2005.

[31] D. Jianbin, Z. Min, Y. Haoming, and J. Min, "Recovery of landwater storage varitions in Chinese Mainland by use of GRACE data," Journal of Geodesy and Geodynamics, vol. 27, no. 3, pp. 68-71, 2007.

[32] X. Su, J. Ping, and Q. Ye, "Study on water storage change using GRACE data in North China," Chinese Science (Earth Science), vol. 42, pp. 917-922, 2012.

[33] D. Jiang, J. H. Wang, Y. H. Huang, K. Zhou, X. Y. Ding, and J. Y. Fu, "The review of GRACE data applications in terrestrial hydrology monitoring," Advances in Meteorology, vol. 2014, Article ID 725131, 9 pages, 2014.

[34] M. Rodell, I. Velicogna, and J. S. Famiglietti, "Satellite-based estimates of groundwater depletion in India," Nature, vol. 460, no. 7258, pp. 999-1002, 2009.

[35] V. M. Tiwari, J. Wahr, and S. Swenson, "Dwindling groundwater resources in northern India, from satellite gravity observations," Geophysical Research Letters, vol. 36, no. 18, pp. 252-260, 2009.

[36] H. Shen, M. Leblanc, S. Tweed, and W. Z. Liu, "Groundwater depletion in the Hai River Basin, China, from in situ and GRACE observations," Hydrological Sciences Journal, vol. 60, no. 4, pp. 671-687, 2015.

[37] M. Rodell, J. S. Famiglietti, J. Chen, S. I. Seneviratne, P. Viterbo, and S. Holl, "Basin scale estimates of evapotranspiration using grace and other observations," Geophysical Research Letters, vol. 31, no. 20, pp. 183-213, 2004.

[38] G. Ramillien, F. Frappart, A. Güntner, T. Ngo-Duc, and A. Cazenave, "Mapping time variations of evapotranspiration rate from GRACE satellite gravimetry," Water Resources Research, vol. 42, Article ID W10403, 2006.

[39] T. H. Syed, J. S. Famiglietti, and D. Chambers, "GRACEbased estimates of terrestrial freshwater discharge from basin to continental scales," Journal of Hydrometeorology, vol. 10, no. 1, pp. 22-40, 2009.

[40] M. Becker, B. Meyssignac, L. Xavier, A. Cazenave, R. Alkama, and B. Decharme, "Past terrestrial water storage (1980-2008) in the Amazon Basin reconstructed from GRACE and in situ river gauging data," Hydrology \& Earth System Sciences, vol. 15, no. 2, pp. 533-546, 2011.
[41] M. Xu, B. S. Ye, Q. D. Zhao, S. Zhang, and J. Wang, "Estimation of water balance in the source region of the Yellow River based on GRACE satellite data," Journal of Arid Land, vol. 5, no. 3, pp. 384-395, 2013.

[42] L. Chevalier, B. Laignel, N. Massei et al., "Hydrological variability of major French rivers over recent decades, assessed from gauging station and GRACE observations," Hydrological Sciences Journal, vol. 59, no. 10, pp. 1844-1855, 2014.

[43] R. R. Muskett and V. E. Romanovsky, "Alaskan permafrost groundwater storage changes derived from GRACE and ground measurements," Remote Sensing, vol. 3, no. 2, pp. 378-397, 2011.

[44] X. G. Hu, J. Chen, Y. Zhou, C. Huang, and X. H. Miao, "GRACE space gravity measurements to monitor the use of the Yangtze River seasonal changes in water storage," Science in China: Earth Science, vol. 36, pp. 225-232, 2006.

[45] M. Zhong, J. Duan, H. Xu, P. Peng, H. Yan, and Y. Zhu, “Trend of China land water storage redistribution at medi- and largespatial scales in recent five years by satellite gravity observations," Chinese Science Bulletin, vol. 54, no. 5, pp. 816-821, 2009.

[46] S.-H. Ye, X.-L. Su, J.-S. Ping, and Q. Huang, "Land water storage variations in China and adjacent areas revealed by the GRACE gravity mission," Journal of Jilin University (Earth Science Edition), vol. 41, no. 5, pp. 1580-1586, 2011.

[47] Q. Li, Z. C. Luo, and B. Zhong, "Terrestrial water storage changes of the 2010 southwest China drought detected by GRACE temporal gravity field," Chinese Journal of Geophysics, vol. 56, no. 6, pp. 1843-1849, 2013.

[48] Y. J. Ding, D. Q. Yang, B. S. Ye, and N. L. Wang, "Effects of bias correction on precipitation trend over China," Journal of Geophysical Research, vol. 62, no. 13, 2007.

[49] D. Bian, B. C. Bian, B. La, C. Wang, and T. Chen, "The response of water level of selin Co to climate change during 1975-2008," Acta Geographica Sinica, vol. 65, no. 3, pp. 313-319, 2010.

[50] S. F. Zhang, D. Hua, X. J. Meng, and Y. Zhang, "Climate change and its driving effect on the runoff in the "Three-River Headwaters' region," Acta Geographica Sinica, vol. 66, no. 1, pp. 13-24, 2011.

[51] M. Xu, Y. Wang, Z. Y. Zhou, S. H. Yi, and B. S. Ye, "Discussion of methods on spatial interpolation for monthly temperature data in Yangtze River basin," Resources and Environment in the Yangtze Basin, vol. 21, pp. 327-334, 2012.

[52] S. Swenson and J. Wahr, "Post-processing removal of correlated errors in GRACE data," Geophysical Research Letters, vol. 33, no. 8, Article ID L08402, 2006.

[53] F. W. Landerer and S. C. Swenson, "Accuracy of scaled GRACE terrestrial water storage estimates," Water Resources Research, vol. 48, no. 4, Article ID W04531, pp. 1427-1434, 2012.

[54] I. Velicogna and J. Wahr, "Measurements of time-variable gravity show mass loss in Antarctica," Science, vol. 311, no. 5768, pp. 1754-1756, 2006.

[55] J. L. Xu, S. Q. Zhang, and D. H. Shangguan, "Glacier change in headwaters of the Yangtze River in recent three decades," Arid Zone Research, vol. 30, no. 5, pp. 919-926, 2013.

[56] Y. Lei, K. Yang, B. Wang et al., "Response of inland lake dynamics over the Tibetan Plateau to climate change," Climatic Change, vol. 125, no. 2, pp. 281-290, 2014.

[57] K. M. Hinkel, R. C. Frohn, F. E. Nelson, W. R. Eisner, and R. A. Beck, "Morphometric and spatial analysis of thaw lakes and drained thaw lake basins in the western Arctic Coastal Plain, Alaska," Permafrost and Periglacial Processes, vol. 16, no. 4, pp. 327-341, 2005. 
[58] K. M. Hinkel, W. R. Eisner, J. G. Bockheim, F. E. Nelson, K. M. Peterson, and X. Dai, "Spatial extent, age, and carbon stocks in drained thaw lake basins on the Barrow Peninsula, Alaska," Arctic Antarctic and Alpine Research, vol. 35, no. 3, pp. 291-300, 2003.

[59] K. Yoshikawa and L. D. Hinzman, "Shrinking thermokarst ponds and groundwater dynamics in discontinuous permafrost near Council, Alaska," Permafrost and Periglacial Processes, vol. 14, no. 2, pp. 151-160, 2003.

[60] L. Li, S. X. Wu, and X. D. Zhu, "The latest fluctuation of the plateau lakes and response to the change of climate and frozen earth environment in the headwaters of Yellow River since 21th century," Journal of Natural Resource, vol. 23, no. 2, pp. 245-253, 2008.

[61] L. H. Cheng and Y. G. Qu, Water and Land Resources and Their Rational Development and Utilization in the Hexi Region, Science Press, Beijing, China, 1992.

[62] J. H. Yang, Z. H. Jiang, and X. Y. Liu, "Influence research on spring vegetation of Eurasia to summer drought-wetness over the northwest China," Arid Land Geography, vol. 35, pp. 1-9, 2012.

[63] S. C. Li, D. L. Li, and P. Zhao, "The climatic characteristics of vapor transportation in rainy season of the origin area of three rivers in Qinhai-Xizang Plateau," Acta Meteorologica Sinica, vol. 67, no. 4, pp. 591-598, 2009.

[64] L. Li, S. Dai, H. Shen, H. Y. Li, and J. Xiao, "Response of water resources to climate change and its future trend in the source region of the Yangtze Rive," Acta Geographica Sinica, vol. 67, no. 7, pp. 941-950, 2012.

[65] T. D. Yao, D. H. Qin, Y. P. Shen, L. Zhao, and S. Y. Liu, "Cryospheric changes and their impacts on regional water cycle and ecological conditions in the Qinghai-Tibetan Plateau," Chinese Journal of Nature, vol. 35, no. 3, pp. 179-186, 2013.

[66] L. Li, H. Y. Shen, S. Dai, J. Xiao, and X. Shi, "Response to climate change and prediction of runoff in the source region of Yellow River," Acta Geographica Sinica, vol. 66, no. 9, pp. 1261-1269, 2011. 

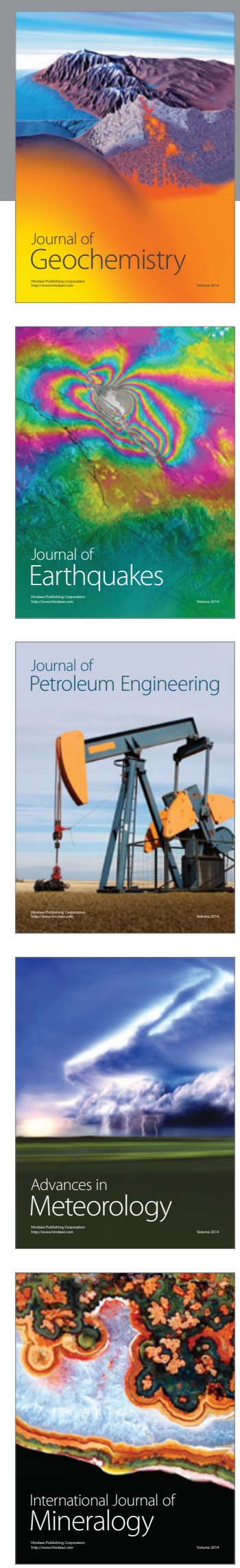
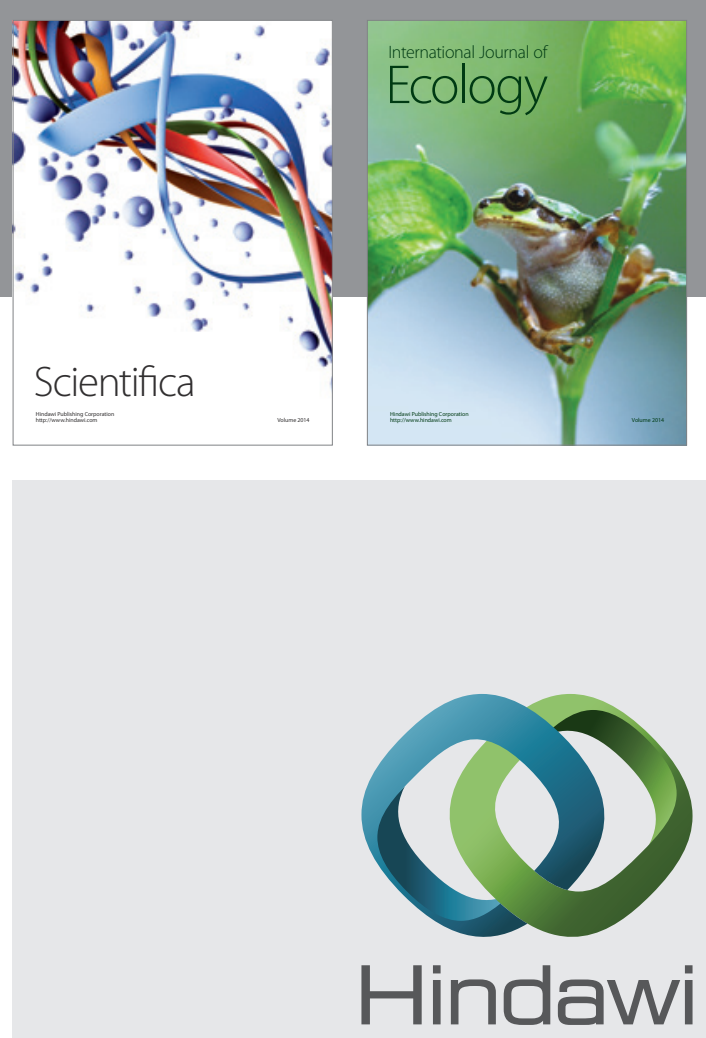

Submit your manuscripts at

http://www.hindawi.com
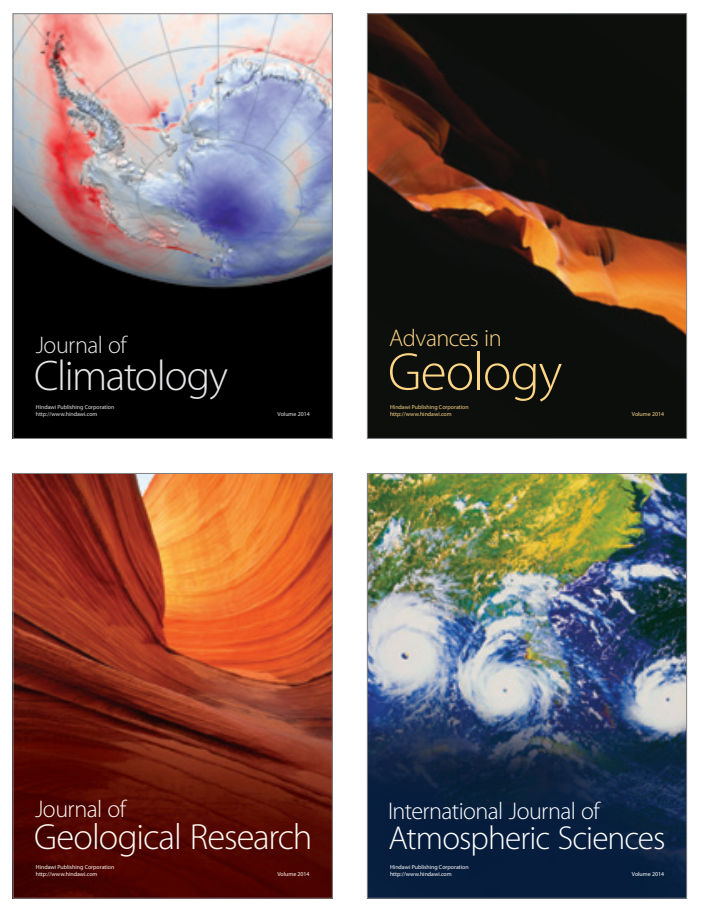

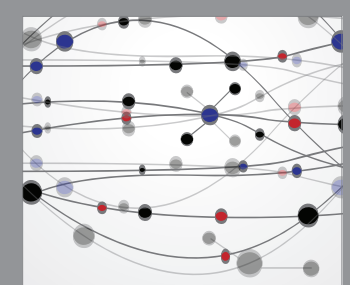

The Scientific

\section{World Journal}
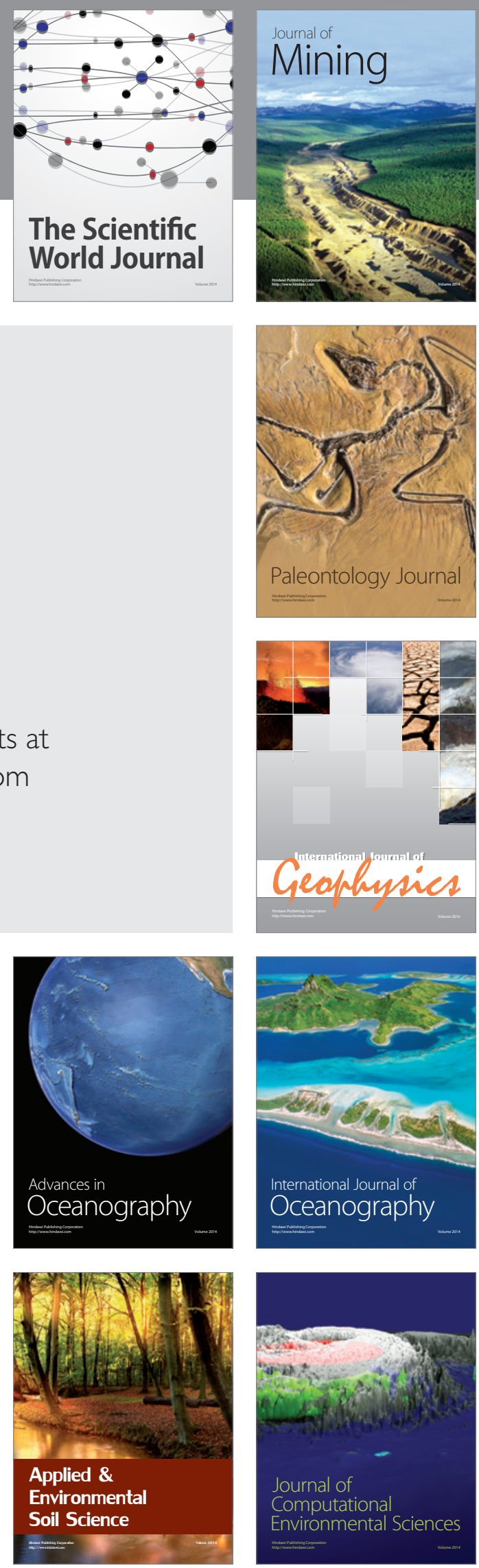